\title{
Desafíos del Año Académico 2021 en la Formación Clínica de Pregrado en Odontología
}

\author{
Challenges of the Academic Years 2021 in Undergraduate Clinical Training in Dentistry
}

\author{
Ramón Fuentes \& Valeska Sánchez
}

Entre los hitos más relevantes que han marcado esta pandemia de Covid-19 no podemos ignorar el día 7 de enero 2020, cuando se logra aislar y decodificar el genoma de un nuevo virus zoonótico que afecta a la población, un tipo nuevo de coronavirus, y el día 23 de enero del mismo año, la ciudad China de Wuhan entra en confinamiento (Fuentes et al., 2020). Actualmente, las cifras mundiales suman más de 100.000.000 de casos totales, con más de 2.000.000 de muertes a nivel mundial. La evolución de esta enfermedad y de las medidas que los diferentes países han adoptado ha sido ampliamente discutidas y los países han creado y adaptado innumerables protocolos para hacer frente a esta nueva situación.

El vertiginoso desarrollo de la inmunización para esta pandemia ha sido una demostración del apogeo científico mundial actual. Hoy, a nivel global, contamos con 11 vacunas desarrolladas y aprobadas al menos en un país. Chile se ha comprometido con la compra de 4 de estas vacunas.

La inoculación de toda la población de un país significa un desafío enorme, tanto por la disponibilidad de vacunas como por la logística de traslado y su aplicación.

En los últimos días hemos sido testigos de un aumento importante de casos activos, principalmente como consecuencia de las reuniones durante las fiestas de fin de año, probablemente también las vacaciones hayan contribuído con este aumento. Debe agregarse además el actuar de algunos grupos que no respetan las normas impuestas por la autoridad sanitaria. Esto último ha llevado a que nuevamente comiencen a decretarse cuarentenas en diferentes comunas de Chile, existiendo en este momento 74 comunas en cuarentena o próximas a entrar a confinamiento.

Durante las cuarentenas, las actividades presenciales de las universidades se ven interrumpidas, a excepción de la actividad de los internos en lugares de práctica. Esto supone un desafío en la formación de los estudiantes de la salud, y especialmente en Odontología, y lleva al análisis de las condiciones y a solicitar, tanto a autoridades sanitarias como universitarias, una excepción.

Al estar por comenzar un nuevo año académi$\mathrm{co}$, se plantean todavía una serie de interrogantes e incertidumbres, las cuales podrían desvanecerse con la llegada de las 4 millones de dosis de la vacuna SINOVAC, pero aún tenemos temas por afrontar: ¿cuánto tiempo llevará inmunizar a la población chilena?, ¿cuánto tiempo debe pasar para lograr el efecto de rebaño?, ¿serán los docentes, especialmente los clínicos, priorizados en la inmunización?, ¿serán priorizados los estudiantes de salud que deben realizar atenciones de pacientes en su formación clínica?, ¿cuál será la orientación para todo el personal que trabaja en las clínicas universitarias?.

Los protocolos que hemos desarrollado para la atención durante la pandemia se mantendrán durante este año 2021, lo que entre otras cuestiones lleva a un análisis de costos que, ya podemos observar, no son menores. 
Los tiempos de atención clínica de cada estudiante probablemente van a disminuir y se verán afectados además por las cuarentenas que posiblemente decrete la autoridad sanitaria.

Asimismo, se espera que las clínicas universitarias hayan realizado, en el caso de que se requiriese, las modificaciones de infraestructura menores y adquisición de equipos necesarios para una adecuada implementación de protocolos de bioseguridad, entre otros puntos para evitar la contaminación vía aerosol, resultante de la práctica clínica odontológica; además de una revisión de los protocolos previos a la pandemia para ajustarlos a la normativa sanitaria vigente (Fuentes \& Aravena, 2020).

Las universidades hemos seguido ingresando una nueva cohorte de estudiantes, lo que en algunos casos significa que no solo se deberán realizar las actividades pendientes, sino también las actividades para los nuevos cursos, que de no ajustarse, supondrá un aumento importante del número de estudiantes en la formación clínica.

El año 2020 fue un año donde escasamente se pudo realizar la formación clínica de los estudiantes, dependiendo de las ciudades donde se encontraban las clínicas universitarias. Las condiciones sanitarias futuras no se vislumbran en el corto plazo demasiado auspiciosas. El gran desafío es poder dar clara información a los estudiantes de los logros de aprendizaje, o competencias profesionales, que este año pudiesen lograr para que ellos tomen la decisión de continuar o esperar un año más. En este sentido, si las decisiones no son consensuadas con los estudiantes, se podrían generar conflictos que a su vez podrían derivar en movilizaciones estudiantiles.

Por otra parte, los cuerpos académicos y los cuerpos colegiados deberán resolver en base a esto si se está en condiciones de entregar las experiencias de aprendizaje clínico donde se logren las competencias profesionales mínimas, las cuales probablemente no serán equiparables con un año normal para aprobar los diferentes niveles de la formación. Resulta este punto relevante en el último nivel de formación intramuro. Pues es ciertamente una ilusión, más que una certeza, que "el año siguiente" recuperen lo no logrado, pues el año próximo tiene sus propios objetivos de aprendizaje. Resulta complejo prolongar un semestre o un año extra para lograr lo no aprendido. Y será también importante determinar si estas decisiones se tomarán en base a la opinión fundada aca- démica de los docentes clínicos o en base a un voluntarismo sin muchos fundamentos.

Por otro lado, existen académicos que reciben remuneraciones sólo por actividades efectuadas, en este caso estamos frente a un análisis diferente, puesto que cada universidad debe velar por su viabilidad financiera. En definitiva, son muchos los elementos a considerar en la discusión para la toma de decisiones, pero lo que no debemos olvidar es que, independiente de la crisis sanitaria a la que estamos expuestos, tenemos una responsabilidad en la formación de cirujanos dentistas que egresaran en los próximos años. Con el tiempo podremos observar los criterios que primaron en las decisiones que cada universidad implementó. Estos son, entre otros muchos, los grandes desafíos de la docencia de pregrado en Odontología en Chile para este año académico 2021. Y por nuestra legislación y normativa universitaria cada universidad deberá tomar sus propias decisiones.

\section{REFERENCIAS BIBLIOGRÁFICAS}

Fuentes, R.; Zaror, C. \& Huanquilef, M. Legislación y normas atingentes a la atención odontológica y el COVID-19. Una perspectiva desde las clínicas universitarias. Int. J. Odontostomat., 14(4):481-8, 2020.

Fuentes, R. \& Aravena, Y. Challenges on dental education post COVID-19. Int. J. Inter. Dent.,13(3):126, 2020

Dirección para correspondencia:

Prof. Dr. Ramón Fuentes

Facultad de Odontología

Universidad de La Frontera

Av. Francisco Salazar 01145

Temuco - CHILE

E-mail: ramon.fuentes@ufrontera.cl 